\title{
Processo clinical caritas: novos rumos para o cuidado de enfermagem transpessoal
}

\author{
Human caring processes: direction for nursing care
}

Proceso clinical caritas: nuevos rumbos para el cuidado de enfermería transpersonal

\section{J ania J acson dos Santos Mathias', Ivete Palmira Sanson Zagonel², Maria Ribeiro Lacerda ${ }^{3}$}

\section{RESUMO}

O objetivo deste artigo é fazer uma reflexão sobre o cuidado humano à luz da evolução teórica das concepções de Jean Watson, tendo em vista as suas novas proposições do que venha ser o homem e sua conexão com o cosmos e as possibilidades de cuidado ante o potencial existente dentro de cada um. Esta forma de cuidar propõe a reestruturação do homem para melhor vivenciar os diferentes momentos da vida, rompendo com os antigos paradigmas em relação ao cuidado de enfermagem. Demonstra as diferentes possibilidades para a prática da enfermagem, bem como os desdobramentos concernentes ao ensino e à pesquisa.

Descritores: Teoria de Enfermagem; Filosofia de Enfermagem; Cuidados de Enfermagem

\begin{abstract}
This article discusses Jean Watson theoretical work on human caring processes, which acknowledges unity of life and men-universe connection. Caring encompasses the reorganization of the human being in order to live deeply the different moments of life, and the breaching of old paradigms in relation to nursing care. Watson's theoretical work suggests different possibilities for nursing practice, teaching, and research.
\end{abstract}

Keywords: Theory of Nursing; Philosophy of Nursing, Nursing Care

\section{RESUMEN}

El objetivo de este artículo es hacer una reflexión sobre el cuidado humano a la luz de la evolución teórica de las concepciones de Jean Watson, teniendo en vista sus nuevas propuestas respecto a lo que es el hombre y su conexión con el cosmos y las posibilidades de cuidado ante el potencial existente dentro de cada uno. Esta forma de cuidar propone la reestructuración del hombre para vivenciar mejor los diferentes momentos de la vida, rompiendo con los antiguos paradigmas en relación al cuidado de enfermería. Demuestra las diferentes posibilidades para la práctica de la enfermería, así como también los desdoblamientos concernientes a la enseñanza y a la investigación. Descriptores: Teoría de Enfermería; Filosofía de Enfermería; Cuidados de Enfermería

\footnotetext{
${ }^{1}$ Mestranda em Enfermagem do Curso de Pós-graduação da Universidade Federal do Paraná - UFPR - Curitiba (PR), Brasil; Membro.do Núcleo de Estudos, Pesquisa e Extensão em Cuidado Humano de Enfermagem (NEPECHE). Bolsista CAPES - Curitiba (PR), Brasil.

${ }^{2}$ Doutora em Enfermagem; Professor Sênior do Programa de Pós-Graduação em Enfermagem da Universidade Federal do Paraná - UFPR - Curitiba (PR), Brasil; Coordenadora do Curso de Enfermagem do Instituto de Ensino Superior Pequeno Príncipe - Curitiba (PR), Brasil.

${ }^{3}$ Doutora em Enfermagem; Professora Adjunto do Departamento e Programa de Pós-Graduação em Enfermagem da Universidade Federal do Paraná - UFPR; Coordenadora do Núcleo de Estudos, Pesquisa e Extensão em Cuidado Humano de Enfermagem - NEPECHE - Curitiba (PR), Brasil.
} 


\section{INTRODUÇÃO}

A evolução científica acompanhada por pesquisadores e educadores aplica-se na reelaboração de conhecimentos a partir de uma visão ampliada que, sem se afastar do que venha a ser científico, atinja novas dimensões. Tornase urgente considerar a necessidade de cuidar do conjunto de sistemas e superorganismos de complexo equilíbrio, que vem sofrendo profunda ação predatória, e que pode estar prestes a ter seu equilibro rompido em cadeia ${ }^{(1)}$.

Nesse sentido, a enfermagem tem buscado repensar a sua prática postura diante da sociedade e seus diversos segmentos. Mais do que estabelecer regras e normas significa contemporizar a sua práxis e, assim, contribuir para a discussão dos novos desafios e tendências que já enfrenta e cuja acentuação se pressupõe no presente milênio ${ }^{(2)}$.

A reflexão sobre Jean Watson ${ }^{(3-4-5-8-12)}$ e sua teoria de cuidado transpessoal surgiu a partir das leituras realizadas sobre as teorias que hoje embasam o cuidado de enfermagem e o sentido de vida em evolução que percebemos contemplados em sua filosofia de cuidado.

A utilização de referenciais teóricos na prática profissional de enfermagem torna-se um demarcador para efetivar ações de cuidar que privilegiem o ser humano inserido em um ambiente, no sentido de restabelecer a saúde por meio do cuidado de enfermagem. As proposições das teóricas de enfermagem auxiliam a organização e sistematização do cuidado, pois ao mesmo tempo oferecem concepções teórico-filosóficas e um método para implementar a prática. Cabe a cada enfermeiro escolher o referencial que melhor se articule à sua realidade para torná-lo visível e com resultados positivos ao profissional e cliente.

Para que o enfermeiro aplique uma teoria de enfermagem, é necessário mergulhar nas proposições, pressupostos e conceitos da teorista, interagir de forma especial e ter afinidade com a ideologia defendida. Essa afinidade é percebida quando o enfermeiro se identifica com o referencial, se coloca presente, vive e sente as mesmas determinações que regem as idéias da teoria proposta. O conhecimento e o aprofundamento das concepções são necessários para a que a apropriação dessas se dê com tamanha segurança, a ponto de serem defendidas como suas. A afinidade exige, ainda, a interrelação do self do enfermeiro, do self do outro (cliente, família, comunidade) à plenitude que rege o universo ou cosmos, conforme preconiza Watson ${ }^{(3-8)}$.

O enfermeiro, ao escolher a teoria, apreende o modo de ser, a história pessoal e profissional da teorista, as formas de aplicação na prática, os desafios a serem transpostos, as facilidades, e também as possibilidades de inovação, de acordo com a realidade de atuação. Assim, necessita acrescentar ao conhecimento que detém sobre a teoria e teorista, o seu próprio preparo individual, para transitar pelo referencial com segurança e apropriação.

Para a utilização da teoria de Jean Watson ${ }^{(3-4-5-8-12)}$, enfermeiro precisa desenvolver seu autoconhecimento, estabelecer contatos com referenciais filosóficos para compreender a dimensão existencial-fenomenológica, bem como as concepções próprias da enfermagem que permeiam sua teoria. Esses conhecimentos talvez se configurem na maior restrição à utilização da teoria acima citada, obstáculo este que os enfermeiros podem ultrapassar, a partir desse preparo.

Jean Watson ${ }^{(3-4-5-8-12)}$ desde sua primeira publicação em 1979 vem aprimorando, aprofundando e ressignificando suas idéias. Sua teoria tem o ser humano como ponto de convergência de todas as ações de enfermagem, a integralidade de corpo, mente e espírito em um processo transpessoal. Diante dessa evolução dos pensamentos e publicações, são visíveis as mudanças que sua teoria apresenta, substituindo os fatores de cuidado pelos elementos do clinical caritas. Ao expor estes elementos, amplia seus conceitos, incluindo a sacralidade do ser cuidado, a conexão do ser humano para um plano que extrapola o concreto e visual e a proposição do bealing como reconstituição do $\operatorname{ser}^{(3-4-5)}$.

Existe ainda uma estreita relação entre a forma de desenvolver o cuidado e o amor a partir do entendimento dessa dualidade expandida para sua forma mais complexa. Essa forma de externar esse sentimento torna propícia a realização da co-existência, e esse ato de acolher o outro estabelece as condições para que se instaure como o mais alto valor da vida ${ }^{(1)}$.

A partir do exposto, o objetivo deste artigo é refletir sobre o cuidado humano à luz da evolução teórica de Jean Watson ${ }^{(3-4-5-8-12)}$,enfatizando a substituição dos fatores de cuidado pelo novo modelo do processo clinical caritas.

\section{A BUSCA DE NOVOS RUMOS PARA O CUIDADO}

A enfermagem contemporânea busca romper os antigos limites cartesianos aos quais outrora estava submetida. Nesta perspectiva, ocorre à valorização de aspectos relacionados à experiência subjetiva do ser humano, o significado pessoal desta experiência, as diferentes formas de enfrentar as situações envolvidas no viver cotidiano do homem, o ser-estar junto com o outro, o saber do outro e as diferenças culturais, dentre outros $^{(6)}$.

Passos significativos foram dados a partir de estudos que envolviam uma infinidade de tendências de ser, estar, pensar e fazer enfermagem, remetendo o pensamento de estudiosas para além da ciência, arte, tecnologia e profissão ${ }^{(7)}$. Consoante a esse pensar, a enfermagem não 
deve ser entendida como a busca da verdade por meio de uma explicação teórica, e sim o constante desenvolvimento da capacidade de fomentar healing*, e assim proporcionar o bem estar dos pacientes ${ }^{(7)}$.

$\mathrm{E}$ nesse momento de transformações fundamentais em que pesquisas e estudos apontam para a necessidade de estabelecer novos paradigmas, as publicações da teorista Jean Watson - autora que há mais de trinta anos vem desenvolvendo estudos e pesquisas na área do cuidado humano e do cuidado transpessoal - são uma das bases essenciais para o aprimoramento de novas práticas do cuidado.

Avançando um pouco além da interpessoalidade, Jean Watson ${ }^{(3-4-5-8-12)}$ propôs uma filosofia do cuidado transpessoal em enfermagem que, ao reconhecer os limites do potencial humano como variáveis ainda não exploradas, busca despertar, em ambos os atores envolvidos no processo de cuidado, o conhecimento de si mesmo como forma de ampliação das próprias capacidades de reestruturação. O processo de crescimento interior constante, que reconhece o ser humano espiritual, gera autoconhecimento, auto-respeito, autocura e entendimento para o autocuidado.

Essa possibilidade humana, que vai além das expectativas antes dimensionadas que envolviam apenas os aspectos objetivos da situação vivenciada, torna claro que o homem possui um potencial que pode ser ampliado, levando-o a descobrir uma maneira satisfatória pela qual consiga vivenciar os diversos momentos da vida ${ }^{(4)}$. Assim, estabeleceu-se a conexão pessoa-natureza-universo, que representa a possibilidade da existência de múltiplas maneiras de ser, saber e fazer, conectadas entre si e ao cosmos, fazendo parte de um todo ${ }^{(9)}$.

A partir dessa perspectiva, a arte de cuidar ganha dimensões próprias da enfermagem que, mais do que uma simples repetição de atividades e tarefas, se traduz por um trabalho complexo que deve ter como finalidade o atendimento às pessoas, por intermédio da ação de cuidar ${ }^{(10)}$. Desenvolver o cuidado com genuína intencionalidade torna possível a conexão com o paciente por meio da empatia, e assim, as prioridades e importâncias traçadas no cuidado desse paciente tornamse comuns com as prioridades e importâncias dele ${ }^{(11)}$.

O cuidado transpessoal de Watson ${ }^{(3-4-5-8-12)}$ determina, a priori, uma atitude de respeito pelo sagrado, que é o outro. Este ser está conectado ao universo, um ser ao outro, sem divisões de espaço, tempo ou nacionalidades, o que a autora, em sua teoria, chama de Caritas e Communitas ${ }^{(3)}$.

A partir do entendimento da sacralidade do ser cuidado e de suas conexões com o cosmos, torna-se possível à enfermeira focalizar a unicidade de si mesma e

* Termo que significa recomposição, restauração e reconstituição e nunca deve ser entendido como cura do outro e na peculiaridade do momento, estando completamente presentes (corpo, mente, espírito), tornam-se capazes de transcender. Criam, dessa maneira, o momento de cuidado transpessoal e assim se abrem a inúmeras possibilidades e modalidades de cuidado $^{(4)}$, dentre as quais se destacam o toque terapêutico, a música, a massagem, meditação, relaxamento, prece, oração, terapia com animais, imagens, humor, dança, oficinas e outros. É nesse momento que a enfermeira torna-se um elemento reconstituidor, realizando assim o cuidado de enfermagem transpessoal.

Ao realizar o cuidado transpessoal, que pode ser expresso de forma amorosa e compassiva, tem-se potencializada a restauração e a totalidade do ser. Para a consecução desse cuidado, Watson ${ }^{(8)}$ resgata que o futuro da enfermagem está ironicamente vinculado a Nightingale ${ }^{(13)}$, uma vez que a enfermeira deve ter em seu íntimo a sensação de ter sido chamada, guiada por um senso profundo de compromisso e acordo ético de serviço humano ${ }^{(3-8-12)}$.

Esse refletir sobre a ação de cuidar constitui uma busca constante e um amadurecimento que leva a novas concepções. Dessa forma, o Processo Clinical Caritas de Watson ${ }^{(3)}$, que hoje embasa o cuidado transpessoal no momento de cuidado, representa a evolução dos fatores curativos anteriormente postulados em sua teoria $^{(7)}$.

O Processo Clinical Caritas vem abordar o outro com delicadeza, com sensibilidade, dando-lhe atenção especial, exercitando uma atenção cuidadosa. É o que pode ser chamado de "atenção de fino trato", que é algo realmente precioso ${ }^{(3)}$.

Watson ${ }^{(3-4-5-8-12)}$ não explicita em sua teoria um modelo de aplicabilidade, seguindo as fases do processo de enfermagem como outras teóricas o fazem. Assim, para facilitar a compreensão apresentamos uma representação dos elementos do clinical caritas. Os números ao lado dos elementos correspondem à ordem que a teorista propõe.

O processo de cuidar em sua completude está envolto pelo elemento existencial-fenomenológico como base para a defesa da sacralidade do ser cuidado, elemento 10, para que o enfermeiro e cliente mobilizem em uma sintonia transpessoal os demais elementos. Para viabilizar esse elemento são necessárias à abertura e atenção aos mistérios espirituais e dimensões existenciais da vidamorte, cuidado da alma e do ser que está sendo cuidado. Reconhecer-se como um ser em evolução, praticar essa evolução, despertar em si mesmo o cuidado transpessoal como forma de compreender-se e auxiliar-se, aceitando a sacralidade do ser e do cuidado e as relações com o cosmos e o divino. Responder aos seus próprios questionamentos e aceitar suas limitações, a complexidade dos seres e o insondável do universo com 
seus mistérios sem respostas.

Cada elemento é ativado na interação com o outro sem necessariamente seguir uma ordem, pois compõem um todo integrado, centrado na recuperação da saúde do ser e desfocado da doença.

No centro da representação encontram-se os elementos 1, 2 e 3, entre o enfermeiro e cliente, demonstrando a relação transpessoal de práticas humanistas para auxiliar o outro a alcançar a conexão com o universo. Nas laterais, como se a representação se unisse por trás e formasse um círculo, há confluência de papéis, aqueles que o enfermeiro desempenha e aqueles que o cliente pode colaborar para alcançar, compondo então, os demais elementos.

(1) Praticar valores humanistas como a gentileza e equanimidade é a prática do amor dentro do contexto da consciência de cuidado. O amor é o sentimento que torna possível ao enfermeiro abrir-se ao outro e, com ele, estabelecer uma convivência e uma comunhão.

(2) Favorecer e sustentar o sistema de crenças e instilar fé e esperança é ser autenticamente presente ao fortalecer e sustentar o profundo sistema de crenças e de subjetividade do seu mundo, vida e do ser cuidado. A manutenção da fé, o respeito à crença do outro são elementos essenciais no ato de conectar-se com o outro. Assim, sem qualquer menosprezo à ciência deve-se instilar fé e esperança como forma de aumentar as capacidades imanentes do ser.

(3) Sensibilidade de si e do outro para alcançar a evolução em conexão com o universo pelo cultivo de práticas próprias espirituais e do eu transpessoal, ultrapassando o próprio ego. Para desenvolver o cuidado transpessoal, faz-se necessário estar em concordância com práticas de evolução do ser, enquanto parte integrante de um todo e em conexão com o universo.

(4) Desenvolver e conservar a relação de ajudaconfiança no cuidado autêntico por meio de atitudes como através de olhar nos olhos do outro, que têm o significado de verdadeiro interesse, e nesse momento torna-se importante cada pequeno detalhe como o sorriso, a postura de nosso corpo, o toque carinhoso, a capacidade de ouvir.

(5) Incentivar a expressão de sentimentos positivos e negativos através da presença como uma conexão profunda entre seu próprio espírito e o da pessoa que está sendo cuidada. As emoções e os sentimentos que as representam fazem parte do perceber-se, sentir-se e pensar do homem e devem ser expressas e valorizadas em cada situação que é vivenciada

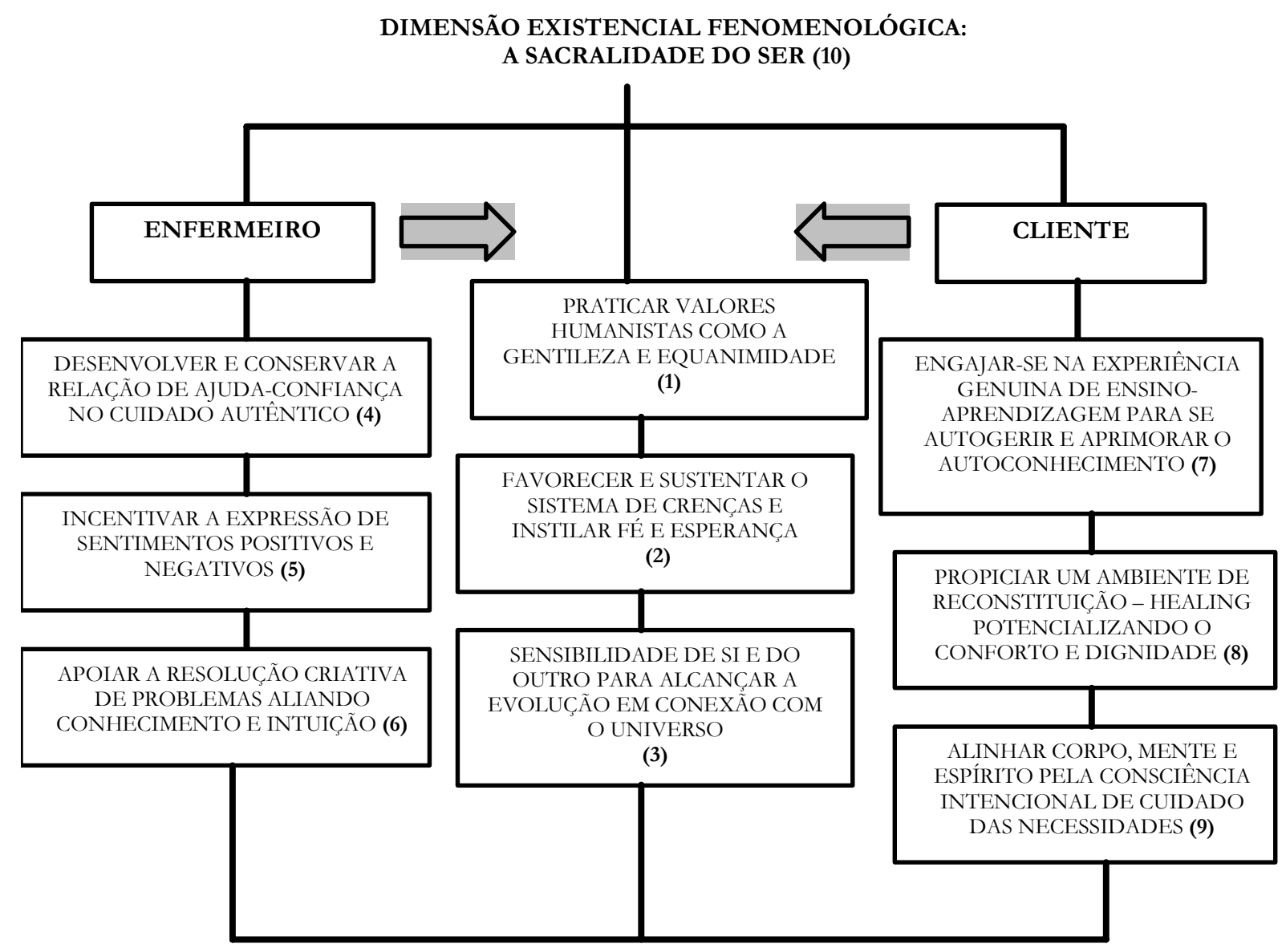


pelo ser, seja essa emoção positiva ou negativa.

(6) Apoiar a resolução criativa de problemas aliando conhecimento e intuição como parte do processo de cuidar, engajar-se em práticas artísticas de cuidado para alcançar a reconstituição. Torna-se importante para o enfermeiro lançar mão, não apenas do conhecimento teórico-prático apreendido no mundo acadêmico científico, mas também de sua intuição, sensocomum, conhecimento estético, ético, pessoal e de suas experiências de vida para realizar o cuidado.

(7) Engajar-se na experiência genuína de ensinoaprendizagem para se autogerir e aprimorar o autoconhecimento, a fim de atender à unidade do ser $\mathrm{e}$ dos significados, tentando manter-se dentro do referencial do outro. Ao estabelecer a verdadeira conexão com o ser cuidado, uma preocupação necessária deve ser em relação às informações e formas alternativas para que a pessoa possa autogerir o seu cuidado ao reconhecer suas próprias necessidades e exercer o autoconhecimento de suas capacidades. Para tanto, deve-se ter em mente a vivência do outro ser como ponto de partida e respeitar suas limitações.

(8) Propiciar um ambiente de reconstituição healing - potencializando o conforto e dignidade em todos os níveis (físico e não físico), ambiente sutil de energia e consciência, pelo qual a totalidade, beleza, conforto, dignidade e paz são potencializados. O enfermeiro deve entender esse ambiente como fatores internos e externos. Procurando estar sensibilizado para captar dificuldades relacionadas ao interior da pessoa em enfrentar a situação que ora vivencia, apresentando opções e capacitando-a a desenvolver mecanismos de enfrentamento dessas situações. Quanto ao ambiente, deverá ser confortável e seguro, além de limpo e saudável.

(9) Alinhar corpo, mente e espírito pela consciência intencional de cuidado das necessidades consiste em ajuda às necessidades básicas, com uma consciência intencional de cuidado, administrando aquilo que é essencial ao cuidado humano, o que potencializará o alinhamento do corpo-mente-espírito, totalidade e unidade do ser em todos os aspectos do cuidado. Nesse elemento, deve ser ressaltado que o ser representa o espírito em um corpo em evolução espiritual e esse fato diz respeito à existência de necessidades básicas ou de sobrevivência relacionadas ao corpo físico e necessidades espirituais que se fazem presentes.

A partir da explicitação dos dez elementos que compõem o processo clinical caritas, entendemos que o enfermeiro deverá efetuar uma transformação em seu próprio íntimo, bem como responder a questões que envolvem a existência de congruência entre os valores e crenças do modelo, valores do enfermeiro, os do grupo ou das pessoas envolvidas no processo, para facilitar sua aplicabilidade ${ }^{(8)}$. Deve considerar se existe o compromisso verdadeiro em expandir a consciência e as ações de cuidado para consigo, para com os outros, o ambiente e o universo. E considerar como fator preponderante a mudança do foco de cuidado da cura para o modelo de cuidado-reconstituição-amor ${ }^{(8)}$.

\section{CONSIDERAÇÕES FINAIS}

O homem, apesar de viver em um mundo onde as relações se estabelecem comunmente de forma equivocada, tem se preocupado com os mistérios que envolvem sua existência conscientizando-se de sua unicidade com o cosmos. A Teoria de Jean Watson ${ }^{(3)}$ instiga a se pensar na Divindade do ser, no amor como manifestação mais elevada, no cuidado que transcende o físico e vai além da matéria e se conecta com o cosmos.

Relendo as formulações de Watson ${ }^{(3-4-5-8-12),}$ percebese que seus estudos avançaram abarcando agora outros aspectos como a expansão de visão de self e pessoa que diz respeito ao espírito em evolução em um corpo físico; a intencionalidade do cuidado como forma de promoção de reconstituição; campo energético, momento de cuidado e conexão com o cosmos, um com o outro e com um todo independente de nacionalidade.

Houve ainda, no decorrer da evolução de sua teoria, um resgate de Florence Nightingale ${ }^{(13)}$ com relação à enfermeira e o chamado interior para o exercício sublime dessa missão de cuidar, pois só assim poder-se-á entender o mais alto grau de amor, calidez e compassividade que cabe externar não só no momento de cuidado, mas como atitudes de vida.

Essa concepção corresponde, sem dúvida, a um estado de ser concreto e constante na vida daqueles que se coadunam com a filosofia de Watson ${ }^{(3-4-5-8)}$. Esta filosofia determina uma profunda transformação no sentido de estar preocupado com o processo evolutivo do ser; impõe um estado de reverência e um sentido de sacralidade em relação à vida, bem como a todas as coisas vivas; estabelece, também, uma compreensão acerca do cuidado voltado para reconstituição do ser, sendo esse fator importante para a capacitação do outro e em promover a sua própria condição de estar bem.

Vale dizer, ainda, que a teoria do cuidado humano de Jean Watson ${ }^{(3-4-5-8-12)}$ traz, como conseqüência, a necessidade de reformular o ensino do cuidado voltado para a formação de futuros enfermeiros a partir da compreensão de que não existe como verdade absoluta e sim, como mais uma possibilidade, entre tantas, de exercer o cuidado especial.

Consideramos relevante salientar a importância de implementação prática desse novo modo de cuidar utilizando os elementos do processo clinical caritas - para que a comunidade científica de enfermagem poder se posicionar quanto a sua aplicabilidade, suas 
potencialidades, a validação de conceitos, ou mesmo a sua rejeição. Somente o exercício intelectual de aprofundar, aplicar e avaliar torna o novo conhecimento familiar aos enfermeiros e, conseqüentemente, trará grandes benefícios aos futuros enfermeiros, àqueles que já atuam e também para o cliente e família, alvo das ações de cuidar.

\section{REFERÊNCIAS}

1. Boff L. Saber cuidar: ética do humano - compaixão pela terra. Petrópolis (RJ): Vozes; 2002.

2. Sá LD. E a enfermagem no século XXI? Rev Bras Enfermagem. 1999; 52(3): 375-84.

3. Watson J. Caring science as sacred science. Philadelphia: FA Davis; 2005.

4. Watson J. Nursing: the philosophy and science of caring.. Boston: Little, Brown; c1979.

5. Watson J. Postmodern nursing and beyond. New York: Harcourt Brace; 1999.

6. 6.Madureira VSF. Os saberes da enfermagem. Rev Bras Enfermagem. 2004; 57(3); 357-60.
7. 7.Lacerda MR Enfermagem: uma maneira própria de ser, estar, pensar e fazer. Rev Bras Enfermagem. 1998; 51(2): 207-16.

8. Watson J. Cuidar em enfermagem além da pósmodernidade. In: Intercâmbio internacional: Bases Teórico-filosóficas da Prática do Cuidar em enfermagem. Rio de Janeiro: Nov 16-19, 2003. [Anotações].

9. Young A, Taylor SG, McLaughlin-Renpenning K. Connections: nursing research, theory, and practice. Saint Louis: Mosby; 2001.

10. Cestari ME. O conhecimento como instrumento de trabalho de enfermagem. Cogitare Enferm. 2002; 7(1): 30-5.

11. Puggina ACG. Administrar o tempo pode mudar o jeito de dizer "bom dia". In: Silva MJP, organizador. Qual o tempo do cuidado? Humanizando os cuidados de enfermagem. São Paulo: Centro Universitário São Camilo: Loyola; 2004. p. 19-28.

12. Watson J. Nursing: human science and human care. A theory of nursing. 2nd printing. New York: National League for Nursing; 1985

13. Nightingale F. Notas sobre enfermagem: o que é e o que não é. São Paulo: Cortez; 1989. 